\title{
O SERVIDOR PÚBLICO NO CONTEXTO DE UMA GESTÃO PÚBLICA HUMANIZADA
}

*Prof. Dr. Gabriel César Dias Lopes, PhD

\section{RESUMO}

Este artigo discute o papel e o comportamento do servidor público, especificamente o gestor, frente aos desafios contemporâneos da administração que apontam principalmente para a necessidade da formação do gestor e de uma atitude de humanização nas ações e serviços prestados. Aborda-se aqui como o serviço público teve que ser redimensionado em função das demandas da Administração atual e do modelo dos serviços privados agora também aplicados ao público e trata da importância de uma formação contínua do servidor público para atender às necessidades do público em geral.

Palavras-Chave: Servidor Público, Administração, Humanização.

\section{ABSTRACT}

This article discusses the role and behavior of the public servant, specifically the manager, in the face of contemporary management challenges that point mainly to the need for training the manager and an attitude of humanization in the actions and services provided. It addresses here how the public service had to be resized according to the demands of the current Administration and the model of private 
services now also applied to the public and deals with the importance of continuous training of the public servant to meet the needs of the general public.

Keywords: Public Servant, Administration, Humanization.

\section{RESUMEN}

Este artículo analiza el papel y el comportamiento del servidor público, específicamente el gerente, frente a los desafíos de gestión contemporáneos que apuntan principalmente a la necesidad de capacitar al gerente y una actitud de humanización en las acciones y servicios prestados. Aquí se aborda cómo el servicio público tuvo que ser redimensionado de acuerdo con las demandas de la Administración actual y el modelo de servicios privados ahora también aplicado al público y aborda la importancia de la capacitación continua del servidor público para satisfacer las necesidades del público en general.

Palabras clave: Servidor Público, Administración, Humanización.

*Gabriel César Dias Lopes - Graduado em: Teologia, Direito, Administração e Recursos Humanos, membro do Conselho Regional de Administração de Minas Gerais - CRAMG No 06-000917D , MBA em Marketing e Gestão Estratégica, Pós-Graduado em Psicanálise, Coordenador do Curso de Pós Graduação Lato Sensu em Psicanálise Clinica da FABIC, Mestre em Educação, Mestre em Administração, Doutor em Educação e um Ph.D em Psicanálise. Membro da International Special Court of Arbitration and Human Rights - Registro: ISCAHRGCDL17/11n2016, Membro da Comissão Científica da Olympus Intellectual Center, Atenas (Grecia), Presidente da LUI - Logos University International. 


\section{INTRODUÇÃO}

O gestor é parte do processo decisório organizacional. Seu comportamento, como o de qualquer outro empregado, é determinado por fatores internos e externos à organização. A compreensão da decisão em si, não traduz de que maneira o gerente se comporta e como chega à escolha de determinada alternativa. Somente analisando o caráter ambíguo da vida organizacional é que se pode compreender como, de fato, se dá o comportamento gerencial. É assim nas instituições privadas e nas públicas.

Nessa última, porém uma série de especificidades, fazem com que o gestor tenha comportamentos diferenciados, principalmente pelo fato de culturalmente o público é tratado de forma diversa e nem sempre respeitosa. Entendendo que o comportamento do gestor é fator que interfere diretamente no comportamento e atuação dos seus subordinados e que a sua formação influencia diretamente na forma de condução do serviço, é que se propõe esse artigo que busca identificar o perfil dos gestores municipais, visando traçar um panorama daquilo que promove e aquilo que emperra os serviços públicos no município de forma que a clientela não seja atendida com a qualidade necessária.

A complexidade de fatores que estão subjacentes na gestão pública por si só situações que merecem um olhar especial de questionamento, sendo uma fonte de infinitas possibilidades de pesquisa. $O$ interesse pela questão advém precisamente pelo fato de observar que o funcionário público municipal, percebe, ainda que de forma não-ordenada, as situações que dificultam a qualidade dos serviços públicos e que poderiam certamente serem resolvidas a partir de uma preocupação quanto à formação técnica e preparação profissional do gestor.

Diante disso, algumas questões aqui levantadas são a respeito da formação do gestor e como essa influência na sua atuação nos serviços públicos municipais. Entendendo que a gestão pública municipal é fortemente influenciada por questões de ordem pessoal, presume-se aqui também que a interferência de questões políticas, a exemplo do nepotismo, em detrimento de aspectos técnicos, prejudica os serviços públicos. Outro aspecto a ser abordado é que a gestão de qualidade com ênfase no 
interacionismo ainda não é uma prática nos serviços públicos municipais e a gestão humanizada é um ideal muito distante da realidade do serviço público municipal. Dessa forma subentende-se que a formação e atualização em serviço pode ser uma opção para os gestores públicos municipais.

Nessa linha de pensamento destacou-se enquanto objetivo discutir o nível de formação dos gestores, e a influência desta na atuação e na qualidade dos serviços oferecidos no município. Pretende-se aqui também historicizar a administração pública contemporânea, caracterizar o servidor público e avaliar o perfil e formação dos gestores municipais, avaliar sob o âmbito da qualidade em gestão, os principais problemas encontrados na administração pública municipal, e o papel desses no encaminhamento de uma gestão humanizada.

A pesquisa aqui proposta se caracteriza como sendo aproximadamente de uma tendência fenomenológico-hermenêutica, como caracterizada por Bicudo (1994) por pretender encontrar a essência da compreensão dos teóricos da administração quanto ao tema proposto, além de interpretar a bibliografia concernente ao assunto.

\section{HISTÓRICO DA ADMINISTRAÇÃO PÚBLICA NO BRASIL}

Todo histórico administrativo seja público ou privado no Brasil têm seus fundamentos no Taylorismo ou nas primeiras escolas da Administração principalmente aquelas baseadas na racionalização do trabalho a exemplo da Escola da Administração Científica ou Escola Clássica da Administração que postulavam que o homem é um ser fundamentalmente racional e, em consequência, ao tomar uma decisão conhece previamente todos os cursos de ação disponíveis, bem como as consequências da opção por qualquer um deles. Motta (1981, pg.66)

Assim, todas as suas determinações são direcionadas pela razão, e esta razão pode - e deve - ser estabelecida e, se possível, quantificada. A física é o modelo a ser seguido. E sua máxima chega a afirmar que só pode ser conhecido o que pode ser medido.

A ação, do homem trabalhador é aquela que maximiza os resultados de sua decisão. Para tanto, e sempre segundo a Escola da Administração Científica, é 
suficiente que persiga o maior lucro (racionalidade econômica) dado que o homem é considerado como um homo economicus.

Ficam, deste modo, sentadas as bases necessárias para o desenvolvimento de uma teoria científica da administração, já que sendo os objetivos do homem assim prefixados torna-se fácil saber suas motivações e, em consequência, determinar de antemão estratégias de ação. Os pressupostos da chamada Teoria Clássica de Administração: - os produtores maximizam seu lucro, dada uma certa tecnologia, e os consumidores maximizam a utilidade, dadas suas preferências e sua renda.

Essa era a máxima de um mundo racional, norteado pelo lucro e a utilidade. Dessa forma, só assim é possível conhecer motivações, estabelecer cursos de ação e, consequentemente, definir conjuntos de estratégias para otimizar os benefícios. $E$ dentro desses pressupostos surgem as organizações que segundo Motta (2001), são respectivamente:

- Um sistema de atividades pessoais ou forças conscientemente coordenadas.

- Um grupo de pessoas, que trabalham juntas, sob orientação de um líder, visando à consecução de um objetivo.

-. Uma integração impessoal, altamente racionalizada, de muitos especialistas que operam para atingir algum objetivo, e sobre a qual é importante uma estrutura de autoridade altamente elaborada. Motta (2001).

O que não se pode perder de vista é que uma organização é antes de tudo um grupo humano, composto por pessoas, presumidamente especialistas que trabalham em conjunto em uma atividade comum. O sucesso do trabalho dessa organização é responsabilidade de todos, mas que o gestor, imbuído das atribuições do líder moderno, tem responsabilidade especial para o sucesso da empresa. Assim, tendo em vista o fato de que atualmente os serviços públicos são (ou deveriam ser) gerenciados por essa nova visão de administração, supõe-se que o tratamento dado a esse setor deve se aproximar ao ideal de empresa em todos os sentidos falando.

\section{O SERVIDOR PÚBLICO}

Nesse contexto, o servidor público é a pessoa física que presta serviços ao estado e às entidades da administração indireta, com vínculo empregatício e mediante 
remuneração paga pelos cofres públicos, sendo estes cargos nas esferas federal, estadual e municipal.

Independente da esfera em que trabalhem, os servidores públicos têm suas regras de trabalho regidas por um estatuto interno dessas esferas e em sua maioria ingressam nesse serviço através de concurso público, conforme classificação, salvo aqueles contratados temporariamente para resolução de demandas. O servidor público, em regra, é regido por uma lei, chamada de estatuto. Por exemplo: as normas sobre os servidores federais estão definidas na lei no 8.112/90 (Estatuto do Servidor Público Federal). Já os empregados públicos, por outro lado, são regidos pelas normas das CLT (Consolidação das Leis do Trabalho), a legislação trabalhista do país.

Assim, os servidores são os agentes públicos, que exercem algum tipo de função pública em vínculo efetivo ou não.

Um servidor público pode temporariamente ocupar uma função de confiança. $\mathrm{Na}$ função, ele pode estar em cargos de direção, assessoramento ou de chefia. Essa função de confiança é a escolha de um servidor público, já concursado, para ocupar um cargo ou posição diferente daquele para o qual ele foi aprovado no concurso público.

No cargo comissionado, uma pessoa pode ocupar uma vaga na administração pública temporariamente, sem ter sido aprovada em concurso. Nesse caso, a contratação acontece através da assinatura de um contrato de trabalho, que deve conter informações como: função que vai desempenhar, valor de salário e tempo previsto para a duração do trabalho. Além disso, os ocupantes de cargos comissionados não têm estabilidade no serviço público, ou seja, podem ser dispensados do trabalho em qualquer momento, conforme a necessidade da administração pública.

\section{AS FUNÇÕES DA ADMINISTRAÇÃO}

As funções universais da Administração são indubitavelmente de previsão: que envolve a avaliação do futuro e o aprovisionamento em função dele; de organização, que proporciona todas as coisas úteis ao funcionamento da empresa e pode ser dividida em organização material e organização social; de comando: Leva a organização a funcionar. 
Seu objetivo é alcançar o máximo retorno de todos os empregados no interesse dos aspectos globais; de coordenação: pois harmoniza todas as atividades do negócio, facilitando seu trabalho e sucesso, sincroniza coisas e ações em suas proporções certas e adapta os meios aos fins. e por fim de controle que consiste na verificação para certificar se todas as coisas ocorrem em conformidade com o plano adotado, as instruções transmitidas e os princípios estabelecidos. O objetivo é localizar as fraquezas e os erros no sentido de retificá-los e prevenir a recorrência.

De acordo com Coelho (2004, p.104) as organizações públicas têm sido forçadas a encontrar maneiras de competir com o setor privado no recrutamento dos poucos talentos remanescente no mercado. Por razões políticas, uma organização pública não pode oferecer salários extremamente altos e incentivos exorbitantes. Uma organização pública pode, por outro lado, estimular um sentimento de orgulho no serviço público e fazer investimentos ativos no desenvolvimento pessoal e profissional de um indivíduo.

Seja na empresa privada, seja no setor público o objetivo final é sempre fazer a organização, instituição funcionar dentro de pressupostos que assegurem um padrão de qualidade, eficácia e eficiência nos serviços prestados. Sendo assim que se busca aqui é identificar onde ocorre o erro na prestação de serviços do município, fazendo que a qualidade seja tão aquém das expectativas da clientela alvo, mas também dos próprios servidores que acabam sendo prejudicados por um ruído na organização.

\section{QUALIDADE EM SERVIÇOS}

De acordo com Meireles (2011) o princípio da eficiência exige que a atividade administrativa seja exercida com presteza, perfeição e rendimento funcional. É o mais moderno princípio da função administrativa, que já não se contenta em ser desempenhada apenas com legalidade, e satisfatório atendimento das necessidades de seus membros exigindo resultados positivos para o serviço público satisfatório atendimento das necessidades da comunidade e de seus membros.

Assim, o papel do atual gestor, além de envolver o aspecto material, envolve aspecto 
humano perfeitamente implícito na gestão de qualidade da empresa ou a instituição atual. Lembrando também que a capacidade social do gestor que determina o seu nível de competência e eficiência e não somente sua capacidade de executar movimentos eficientes dentro do tempo estabelecido.

Quanto maior a integração social no grupo de trabalho, tanto maior a disposição de produzir. Se o gestor é o técnico preparado, mas, porém, não está socialmente integrado, sua eficiência sofrerá a influência de seu desajuste social. Por ser o trabalho é uma atividade tipicamente grupal, o gestor é aquele que entende que o nível de produção é influenciado mais pelas normas do grupo do que pelos incentivos salariais e materiais de produção. A atitude do empregado diante do trabalho e a natureza do grupo social do qual ele participa são os fatores decisivos da produtividade.

Para Minayo (2004) já passamos do estágio de organização humana em que a comunicação e a colaboração eram asseguradas pelas rotinas estabelecidas. A sociedade civilizada alterou seus postulados. Passamos de uma sociedade estável para uma sociedade adaptável, mas negligenciamos a habilidade social. Nossa capacidade de colaborar com os outros está se deteriorando. Somos tecnicamente competentes como nenhuma outra idade na História o foi, e combinamos isto com uma total incompetência social”. É necessária a formação de uma elite social capaz de recobrar a cooperação.

Ainda para Minayo (2004, p. 22) o servidor público trabalha com o universo de significados, motivações, aspirações, crenças, valores e atitudes, o que corresponde a um espaço mais profundo das relações, dos processos e dos fenômenos que não podem ser reduzidos à operacionalização de variáveis. O que se levanta aqui é que essa capacidade social, interativa pode ser destacada pela formação técnica do gestor e infelizmente por conta de questões políticas isso é negligenciado nos municípios do interior, causando prejuízos nos serviços públicos.

O grande desafio do gestor é formar uma elite capaz de compreender e de comunicar, com chefes democráticos, persuasivos e simpáticos a todo o pessoal, mas alguém que saiba impor limites, dialogar, e deixar sempre explícita a situação que seja no serviço privado, seja no serviço público, existe um empregador comum e que como todo e qualquer empregador merece, respeito, deferência e qualidade no atendimento: a população. E atender bem a população ultrapassa qualquer vínculo político e perpassa pela atitude humana e profissional. 
Por isso atualmente se fala tanto em gestão humanizada que nada mais é que buscar a unidade entre os que trabalham, incentivando o bom convívio, os momentos de alegria, a dissipação de possíveis atritos. Esta inquietação reflete-se na busca do equilíbrio entre a satisfação das necessidades dos funcionários e os objetivos organizacionais, que no caso da organização pública, é a excelência e qualidade no serviço público. Percebe-se que a implantação da gestão humanizada trará mudanças significativas no gerenciamento relativo às competências do gestor público e ao clima de satisfação para os funcionários públicos.

Isto ocorre, porque a gestão humanizada afetará sensivelmente o somatório das percepções, opiniões, atitudes e comportamentos individuais. (CALDAS, 2006, p. 47).

\section{O CONCEITO DE GESTÃO HUMANIZADA}

Esse conceito pode ser entendido como a adaptação do processo produtivo às necessidades das pessoas envolvidas, de forma que a produtividade desejada conviva harmoniosamente com o bem-estar e a satisfação dos trabalhadores.

Pode se afirmar que esse conceito apesar de ter nascido na empresa privada e em um contexto bastante recente, vem repercutindo na esfera pública principalmente tendo em vista os custos envolvidos entre contratações e demissões e a mudança e alteração na mão-de-obra e a forma como isso afeta a produção.

Assim, a ideia de ter funcionários satisfeitos é vista atualmente não apenas como uma força produtiva, mas também como fator de lucro para empresa. No caso do serviço público, entende-se que o funcionário valorizado, se sente parte do processo e ciente de sua importância para esse, cria um ambiente de satisfação ao cliente que em caso principalmente do serviço público é de vital importância para a gestão.

Desta forma, a humanização dos processos já passa a ser conteúdo cientifico entre as principais escolas de gestão do mundo e passa a ser efetivada em diversos setores a partir de 4 pilares principais: Observação das necessidades dos envolvidos no processo; Comunicação eficaz entre liderança e liderados; Criação de laços e proximidade entre os trabalhadores envolvidos; Adequação do processo às necessidades observadas, quando possível. 
O estabelecimento desses pilares fortalece o encaminhamento de melhores relações e melhor produtividade em qualquer setor de serviço seja ele público ou privado.

\section{O PAPEL DE LIDERANÇA DO GESTOR}

Acredita-se que a formação do líder é um pressuposto para o alcance de uma gestão humanizada que garanta a qualidade total nos serviços públicos em nível municipal. De acordo com Bresser e Peter (2005, p. 27) entendendo que Administração Pública compreende o conjunto de atividades diretamente relacionadas com a execução de tarefas ou incumbências consideradas de interesse público, ou comum, numa coletividade ou organização estatal, o papel da administração atualmente é ampla.

À nova administração pública não basta ser efetiva em evitar o nepotismo e a corrupção: ela tem que ser eficiente ao prover bens públicos e semipúblicos, que cabe ao Estado diretamente produzir ou indiretamente financiar.

\section{CONSIDERAÇÕES FINAIS}

Certamente a implementação de uma gestão humanizada parte muito da postura do gestor e de sua equipe de trabalho, sua visão de mundo e suas metas par a empresa. Em se tratando de serviço público as dificuldades são ainda maiores e as variáveis infinitas. O gestor formado e informado fará a diferença e a mudança de concepção em relação à administração pública fará toda a diferença.

No Brasil, especificamente onde as práticas públicas são notadamente clientelistas, assistencialistas e viciadas, não é fácil incorrer com nova visão e novas práticas. E toda mudança é vista em parte como vertical e ditadora.

Apenas uma educação para a gestão pública poderá trazer a implantação de serviços de maior e melhor qualidade e essa atitude precisamente deve partir do gestor para que o funcionalismo se engaje nas mudanças. 


\section{REFERENCIAS}

ARAÚJO, L. C. G. Organização, sistemas e métodos e as tecnologias de gestão organizacional. São Paulo: Atlas, 2005.

BENNIS, Warren. A formação do líder. São Paulo: Atlas, 2006.

BERNARDES, C. Sociologia Aplicada à Administração: o comportamento organizacional. São Paulo. Atlas, 2006.

BICUDO, Maria Aparecida Viggiani. A pesquisa qualitativa fenomenológica à procura de procedimentos rigorosos. In: Fenomenologia: confrontos e avanços. São Paulo: Cortez, 2000. p. 70-102.

BUTTERWORTH, Bill. Como Formar Equipes Bem-sucedidas. São Paulo. Futura.2007.

CALDAS. P.S. Gestão humanizada: novos caminhos. Salvador, IAT, 2006.

COELHO, E. M. Gestão do conhecimento como sistema de gestão para setor público. Revista do Servidor Público. Rio de Janeiro, ano 55, № 1, 2004.

CURY, A. Organização e métodos: uma visão holística. São Paulo: Atlas, 2006.

CHIAVENATO, I. A Administração de Empresas. Uma abordagem Contingencial. São Paulo, Mac Graw Hill, 2002.

Administração nos Novos Tempos. Rio de Janeiro.Elsevier,2004. DAVIS, William. Mitos da administração: tudo o que você pensa que sabe pode estar errado. São Paulo: Negócio Editora, 2006. 
DECRETO № 7.203, DE 4 DE JUNHO DE 2010. Disponível em http://www.planalto.gov.br/ccivil 03/ Ato2007-2010/2010/Decreto/D7203.html

MADUREIRA, C. A formação contínua no novo contexto da administração pública: possibilidades e limitações. Petrópolis: Vozes, 2005.

MEIRELLES, Hely Lopes. Direito Administrativo Brasileiro.37ํㅗㄹ ed. atual., São Paulo.2011Revista dos Tribunais, 1.

MINTZBERG, Henry. Criando Organizações Eficazes. Estruturas em Cinco Configurações. São Paulo: Atlas, 2008.

Ascensão e Queda do Planejamento Estratégico. Porto Alegre: Bookman, 2004. Trad.: M. A. Carpigiani.

MINAYO, M. C. S. Pesquisa Social: teoria, método e criatividade. Petrópolis: Vozes, 2004.

MOTTA, Paulo Roberto. Gestão Contemporânea: A Ciência e a Arte de Ser Dirigente. 12 ${ }^{\mathrm{a}}$ ed. Rio de Janeiro: Record, 2001.

- Participação e Descentralização Administrativa: Lições de Experiências Brasileiras. In Revista de Administração Pública. Rio de Janeiro 28 ( 3): 174- 94, Jul/Set 1994. Acessado em 10 de setembro de 2015.

PEREIRA, Luiz Carlos Bresser; SPINK, Peter Kevin. Reforma do Estado e Administração Pública Gerencial. Tradução Carolina Andrade. 5. ed. Rio de Janeiro: Ed. FGV, 2003.

REZENDE, D. A, CASTOR, B. J. V. Planejamento estratégico municipal: empreendedorismo participativo nas cidades, prefeituras e organizações públicas. 2. ed. Rio de Janeiro: Brasport: 2006. 